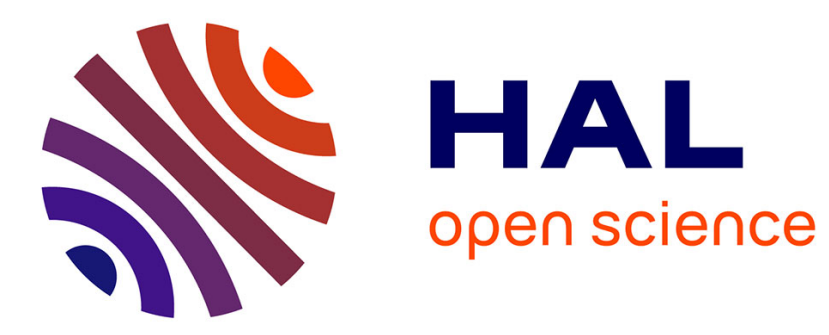

\title{
Northern Chile intermediate-depth earthquakes controlled by plate hydration
}

Leoncio Cabrera, Sergio Ruiz, Piero Poli, Eduardo Contreras-Reyes, Axel

Osses, Renzo Mancini

\section{To cite this version:}

Leoncio Cabrera, Sergio Ruiz, Piero Poli, Eduardo Contreras-Reyes, Axel Osses, et al.. Northern Chile intermediate-depth earthquakes controlled by plate hydration. Geophysical Journal International, 2021, 226 (1), pp.78-90. 10.1093/gji/ggaa565 . hal-03197367

\section{HAL Id: hal-03197367}

\section{https://hal.univ-grenoble-alpes.fr/hal-03197367}

Submitted on 13 Apr 2021

HAL is a multi-disciplinary open access archive for the deposit and dissemination of scientific research documents, whether they are published or not. The documents may come from teaching and research institutions in France or abroad, or from public or private research centers.
L'archive ouverte pluridisciplinaire $\mathbf{H A L}$, est destinée au dépôt et à la diffusion de documents scientifiques de niveau recherche, publiés ou non, émanant des établissements d'enseignement et de recherche français ou étrangers, des laboratoires publics ou privés. 
1 Northern Chile Intermediate-Depth Earthquakes Controlled by Plate Hydration

2 Leoncio Cabrera ${ }^{1 \dagger}$, Sergio Ruiz ${ }^{1}$, Piero Poli ${ }^{2}$, Eduardo Contreras-Reyes ${ }^{1}$, Axel Osses $^{3}$ and Renzo Mancini ${ }^{1}$

4

$5{ }^{1}$ Departamento de Geofísica, Facultad de Ciencias Físicas y Matemáticas, Universidad de Chile.

$6 \quad{ }^{2}$ ISTerre Institut des Sciences de la Terre, CNRS, Université Grenoble Alpes.

$7 \quad{ }^{3}$ Departamento de Ingeniería Matemática y Centro de Modelamiento Matemático UMI 2807

8 CNRS, Facultad de Ciencias Físicas y Matemáticas, Universidad de Chile.

9

10 Corresponding author: Leoncio Cabrera (leoncio.cabrera@univ-grenoble-alpes.fr)

11 Université Grenoble Alpes, ISTerre CS 40700 38058, GRENOBLE Cedex 9

12

$13 \uparrow$ Currently at ISTerre Institut des Sciences de la Terre, Université Grenoble Alpes.

14 


\section{Abstract}

17 We investigate the variations of the seismic source properties and aftershock activity using

18 kinematic inversions and template-matching, for six large magnitude intermediate-depth

19 earthquakes occurred in northern Chile. Results show similar rupture geometry and stress drop

20 values between 7-30 MPa. Conversely, aftershocks productivity systematically decreases for the

21 deeper events within the slab. Particularly there is a dramatic decrease in aftershock activity

22 below the $400-450^{\circ} \mathrm{C}$ isotherm-depth, which separates high and low-hydrated zones. The events

23 exhibit tensional focal mechanisms at unexpected depths within the slab, suggesting a deepening

24 of the neutral plane, where the extensional regimen reaches the $700-800^{\circ} \mathrm{C}$ isotherm-depth. We

25 interpret the reduction of aftershocks in the lower part of the extensional regime as the absence

26 of a hydrated-slab at those depths. Our finding highlights the role of the thermal-structure and

27 fluids in the subducting plate, in controlling the intermediated-depth seismic activity and shed

28 new light in their causative mechanism.

30 Keywords: Intraslab Intermediate Depth Earthquakes, Aftershock, Chile, Subduction, Slab. 
35 Rupture mechanism of intermediate-depth earthquakes (IDEs) is one of the biggest open

36 questions in seismology (Frohlich, 2006; Houston, 2015). They occur mostly at subduction zones

37 in the so called double seismic zones (DSZ), where two parallel seismicity planes are observed.

38 The upper seismicity plane (USP) is inferred to occur within the subducting oceanic crust and/or

39 the upper mantle due to dehydration reactions (Hacker et al., 2003; Kirby, 1995). In contrast, the

40 lower seismicity plane (LSP) occurs in the lithospheric mantle, and its mechanism is still under

41 debate (Ferrand et al., 2017; Ohuchi et al., 2017; Peacock, 2001; Reynard, 2010). Hypothesis for

42 this process include dehydration-embrittlement of antigorite (Peacock, 2001), reactivation of pre-

43 existing shear zones (Reynard, 2010) and quasi-adiabatic shear-heating instabilities (John et al.,

44 2009). Furthermore, laboratory experiments also suggest that faulting at intermediate depths may

45 occur under dry conditions (Ohuchi et al., 2017) or by dehydration-driven stress transfer under

46 partially hydrated mantle conditions (Ferrand et al., 2017).

47 The DSZ is usually characterized by compressional deep events within the oceanic lithospheric

48 mantle in trench-outer rise regions prior to subduction, while the upper part of the oceanic

49 lithosphere is affected by a tensional regime. This stress field in the trench-outer rise region is

50 controlled by the plate bending caused by the interplay of slab pull forces and the rheology of the

51 oceanic lithosphere (Contrereas-Reyes \& Osses, 2010). Furthermore, based on a worldwide

52 compilation of trench outer rise earthquakes, the position of the neutral plane of the stress field

53 within the oceanic lithosphere have been estimated to be approximately coincident with the $400^{\circ}$ -

$54450^{\circ} \mathrm{C}$ isotherm-depth (Seno \& Yamanaka, 1996). Likewise, Ruiz \& Contreras-Reyes (2015) and

55 Carrasco et al., (2019) found that tensional outer rise events are confined to the upper oceanic

56 lithosphere to isotherm-depths shallower than $400^{\circ} \mathrm{C}$ offshore central Chile. Off Japan, Kita et 
57 al., (2010) reported that the transition from upper tensional to compressional intraplate

58 earthquakes occur at $22 \mathrm{~km}$ beneath the base of the Eurasian plate beneath Tohoku. However,

59 this transition occurs only $\sim 10 \mathrm{~km}$ beneath the upper plate beneath Hokkaido. The authors

60 attribute this difference to the complexity of the oblique subduction beneath Hokkaido, and they

61 further pointed out that the stress regime is the combination of two stress fields: (i) the

62 bending/unbending force, and (ii) the thermomechanical and petrological forces.

63 Although IDEs are characterized by shear slip on faults similar as inland crustal or interplate

64 earthquakes, anomalous behavior is often observed for the first ones such as thermal-dependence

65 radiated seismic energies (Wiens, 2001), significant non-double-couple mechanisms (Richardson

66 \& Jordan, 2002), and high stress drops (Frohlich, 2006; Poli et al., 2014; Houston, 2015) among

67 others. A remarkable characteristic of intermediate and deep earthquakes is their general lower

68 aftershock productivity as compared with shallower events (Frohlich, 1987; Wiens et al., 1994;

69 Zhan, 2014; Houston, 2015), although few cases with large activity exist (Wiens et al., 1994).

70 Aftershocks activity has been related to fault properties as state of stress (Shebalien \& Narteau,

71 2017), rupture processes (Poli et al., 2016), seismic coupling (Hainzl et al., 2019) and the

72 thermal state of the slab, with colder slabs showing a greater number of aftershocks (Wiens \&

73 Gilbert, 1996). A main issue is to understand if this general decrease in the number of

74 aftershocks is real, or it is due to the lack of near-field data (Li et al., 2018). It is thus

75 fundamental to tackle this issue, to better assess the aftershock activity (Dascher-Cousineau et

76 al., 2020) and get new insights about the mechanism(s) and physical conditions controlling the

77 occurrence of IDEs.

78 Since 2010, six intermediate-depth events with magnitudes (Mw) greater than 6 occurred in

79 northern Chile between $17^{\circ} \mathrm{S}$ and $21^{\circ} \mathrm{S}$ (Figure 1 and Table S1), where the Centro Sismológico 
80 Nacional de la Universidad de Chile (CSN; Barrientos et al., 2018), Integrated Plate Boundary

81 Observatory Chile (IPOC; GFZ, \& CNRS-INSU, 2006) and Central Andean Uplift and the

82 Geodynamics of the High Topography (CAUGHT; Beck et al., 2010) seismic networks have

83 been deployed (Figure 1a). These events are of main interest for several reasons. First, they are

84 registered by a dense network of broad-band and strong-motion sensors in the near-field

85 providing an opportunity to avoid problems with detection levels (Poli et al., 2016; Shebalien \&

86 Narteau, 2017; Zhan et al., 2014). Second, the six events are located in a very limited volume,

87 reducing issues related with attenuation and other propagation effects, which are possibly

88 affecting the estimation and thus the comparison of source properties (Prieto et al., 2012).

89 Finally, their magnitudes $(\mathrm{Mw} \sim 6.3)$ and focal mechanisms are similar (Figure 1$)$. We thus have

90 a unique opportunity to compare source properties and aftershock activity, with limited bias due

91 to propagation and rupture geometry. In addition, according to the CSN catalogue they exhibit

92 different aftershock productivity. For the shallowest event (E1 in Figure 1c), there are more than

9340 aftershocks reported, including some of them with magnitude equal or greater than Mw 4.0

94 (see Supplementary Information). For the deeper ones there is a decrease in the number of

95 aftershocks with no aftershocks for the deepest event (E6 in Figure 1c).

96 To better characterize if differences in between these events exist, we study their aftershock

97 activity and rupture properties, using template matching (TM) and kinematic inversions (KI).

98 Furthermore, we developed a thermal model using the finite element method (FEM), with the

99 aim of analyze the impact of slab temperature on seismic behavior. In the next sections, the 100 tectonic setting and methodologies used in this study followed by their respective results are 101 described, and finally the discussions and conclusions are presented. 


\section{Tectonic Setting}

104 The northern Chilean convergent margin is characterized by the subduction of the oceanic Nazca

105 plate beneath the continental South American plate (Figure 1) at a currently convergence rate of

$106 \sim 67 \mathrm{~mm} / \mathrm{a}$ (Khazaradze \& Klotz, 2003), although the average convergence rate during the last 20

$107 \mathrm{Ma}$ is about $85 \mathrm{~mm} / \mathrm{a}$ (DeMets et al. 2010). The Nazca plate in the study region $\left(18^{\circ}-21^{\circ} \mathrm{S}\right)$ was

108 formed in the East Pacific Rise 45-52 Ma (Mueller et al., 2008), whereas its crustal thickness is

109 6-7 km thick inferred by seismic constraints (Patzwahl et al., 1999; Ranero and Sallarès, 2004;

110 Contreras-Reyes et al., 2012; Maksymowicz et al., 2018). The northern Chilean margin has a

111 poorly sedimented trench $(<200 \mathrm{~m}$; Maksymowicz et al., 2018) due to the reduced sediment

112 supply from the Andes in the extremely arid region of the Atacama Desert. The continental slope

113 is steep as the frontal part of the margin lacks a well-developed frontal prism (Contreras-Reyes

114 2018; Maksymowicz et al., 2018).

115 The northern Chilean margin has undergone subduction erosion since at least the Jurassic, which

116 is inferred from the eastward migration of the volcanic arc (e.g. Rutland, 1971; Stern, 2011) as

117 well as the long-term arcward retreat of the trench, crustal thinning and subsidence of the outer

118 forearc (e.g., Kukowski \& Oncken 2006; Contreras-Reyes 2018). Long-term subduction rates for

119 northern Chile have been estimated with values of $40-45 \mathrm{~km}^{3} \mathrm{Myr}^{-1} \mathrm{~km}^{-1}$ (Kukowski \& Oncken

120 2006). On the other hand, the oceanic Nazca plate presents well developed tensional faults seen

121 in the bathymetric data (Geersen et al., 2018), which were formed by bending of the oceanic

122 plate (Ranero et al., 2005). These bend faults provide the pathways for seawater infiltration 
123 reaching the oceanic mantle according to seismic and geodynamic studies (see Contreras-Reyes

$124 \&$ Osses, 2010 and references therein).

\section{Aftershock productivity}

\subsection{Detection of aftershocks using template matching}

128 The six studied IDEs have tensional focal mechanism and span a range of depth from 90 to 130

$129 \mathrm{~km}$ (Figure 1), in a region where a double seismic zone (DSZ) has been previously reported

130 (Comte et al., 1999; Dorbath et al., 2008; Sippl et al., 2018; Florez \& Prieto, 2019) and the

131 seismic catalog has magnitude of completeness Ml 3.5 (Barrientos et al., 2018). It is thus likely

132 that aftershocks are missing for some the studied events, which is improved using template 133 matching (TM).

134 TM has been widely used to detect events in aftershocks sequences, where seismicity is known 135 to repeat (Shelly et al., 2007; Peng \& Zhao, 2009; Frank et al., 2017; Li et al., 2018). In a similar 136 way, we here apply TM to improve the detection of aftershocks following the analyzed events

137 (Figure 1). We base our analysis on continuous three-component velocity seismological data 138 from the CSN, IPOC, and CAUGHT seismic networks, using the five nearest stations to the 139 source region of each event (Figure S15). Data were continuously recorded at a sampling rate of $140100 \mathrm{~Hz}$ for IPOC and CSN stations, and $40 \mathrm{~Hz}$ for CAUGHT stations. To detect non-reported 141 aftershocks, we searched for events with similar waveforms to those reported as mainshock and 142 aftershocks for the CSN (template candidates, see Supplementary Information). A space-time 143 window needs to select reference events and build templates. A large window implies including 
144 more events, but also more background events as well, while a smaller window decreases this

145 effect, but is more likely to miss some aftershocks. Since the six earthquakes have similar

146 characteristics such as magnitude, focal mechanism, hypocenter and station coverage, we use the

147 same spatial and temporal scale for all of them in order to preserve a homogeneous criterion that

148 allows their comparison. After some tests with different windows size and considering some

149 previous works (e.g., Persh and Houston, 2004; Dascher-Cousineau et al., 2020) we define the

150 spatial limit using a 3D radius of $25 \mathrm{~km}$ from each hypocenter, and 25 days of data after each

151 mainshock, as this is the maximum number of days for which the five stations closest to each

152 event were operating continuously. Both continuous data and template waveforms were bandpass

153 filtered from 5 to $10 \mathrm{~Hz}$ because this frequency range exhibits better signal to noise ratios, and

154 decimated to $25 \mathrm{~Hz}$. To select high-quality template events, we follow Frank et al. (2017) and we

155 estimate the signal-to-noise ratio (SNR) on the vertical component as the ratio between the RMS

156 velocity during the first $25 \mathrm{~s}$ of the P-wave and the RMS velocity during a $25 \mathrm{~s}$ of noise before

157 the P-wave arrival time. Only template candidates with SNR $>5$ in at least 3 stations are used as

158 templates. We define the resulting template waveforms as $30 \mathrm{~s}$ time windows that start $5 \mathrm{~s}$ before

159 event's P-wave arrival at each station. Then we calculate the correlation coefficients between

160 template waveforms and continuous data in a sliding window that preserves the seismic

161 moveouts (Frank et al., 2017), to get a time series that represents the similarity of the continuous

162 data to the matched-filter template. We search sample-by-sample considering a detection

163 threshold that is 10 times the median absolute deviation (MAD) of the correlation sum to detect

164 event significantly similar to the template. Events detected with this criterion, are then

165 considered to occur at the same hypocenter (determined by the CSN) as their template, and we

166 estimate their magnitude by computing the median amplitude ratio between the template event 
167 and the aftershock over the 5-station network, assuming that a tenfold increase in amplitude

168 corresponds to one unit increase in magnitude. Figures 2b-c show an example for E2 and E5,

169 where using the mainshocks waveforms as templates, two new detections with inferred

170 magnitudes (Mw) of 1.8 and 2.7 occurred four days (for E2) and some hours (for E5) after

171 mainshocks.

172 To avoid redundancy of events detected by multiple templates, we remove detections within $30 \mathrm{~s}$

173 of another detections, by keeping the event with the highest network correlation coefficient.

174 Finally, we use the new catalogue (including CSN and new detected aftershocks) as templates

175 candidates, and the process is repeated once.

\subsection{Aftershock Activity}

177 Figure 3a shows all new detections and catalog events, for 25 days after each mainshock. As is 178 common for aftershock sequences, the number of events decreases over time, with a higher

179 concentration close to the mainshock. On the other hand, the number of aftershocks shows a 180 clear reduction as function of depth, down to E6 that is showing no aftershocks (Figures 3a-c).

181 The most productive event is E1, located just $\sim 7 \mathrm{~km}$ from the top of slab (Figure 1). For this 182 earthquake, we used 45 events as templates, and we found 2044 aftershocks, nearly 47 times 183 more.

184 It is important to highlight that there are no aftershocks reported in the CSN catalog for E2, E5, 185 and E6. For these events, we use the mainshock waveforms for detection. This strategy permits 186 to find new events for E2 and E5, suggesting that the sole main event waveforms can improve 187 the detection. Figure 2 shows an example of detections for E2 and E5 using mainshock 
waveforms as templates (see Table S2 for more details about detections). According to the above, lack of detection seen for E6 is a robust feature of our analysis.

\section{Thermal structure}

\subsection{Thermal-Fluid Numerical Model}

To assess the thermal conditions at the depth of the analyzed events, we developed a 2D-thermal model using Finite Element Method (FEM) for northern Chile, along the BB' profile (Figure 1).

195 The model is constrained by the plate geometry of SLAB2.0 (Hayes et al., 2018), hypocenter 196 data, and published thermal parameters in the area (see Table S5).

\subsubsection{Numerical Model}

198 The thermal subduction model consists in a two-dimensional finite element discretization of a 199 coupled system of a heat equation for the temperature and and the Stokes's system for the 200 subducting lithospheric plate speed and asthenospheric fluxes. The heat equation is given by:

$$
-\kappa \nabla^{2} T+\vec{u} \cdot \nabla T-Q=0
$$

201 in the region of interest $\Omega$, where $T$ is the temperature and the first term corresponds to heat

202 diffusion where $\kappa$ is the thermal diffusivity depending on space (ratio of the thermal conductivity $203 k$ and the thermal capacity $\rho c_{p}$ of the media), the second term corresponds to the heat transport 204 due to lithospheric speed and asthenospheric fluxes $\vec{u}$, and the last term stands for the external heat 205 sources such as radiogenic or frictional heat. No friction heat effects are considered in this study 206 since in the case young lithospheres the effects of friction can be neglected (Vöelker et al., 2011). 
207 Thermal effects due to the subducted eroded material above the incoming/subducting lithosphere 208 are also neglected for the sake of model simplicity.

209 Given a velocity field $\vec{u}$ in the whole region $\Omega$, we obtain the steady state temperature $T$ as the 210 limit of $T_{n}$ solution of the following variational problem discretized with Lagrange finite elements

211 of type $\mathrm{P} 2$ (space $V_{h}$ ) and iterating for $n \geq 1$ starting from $T_{0}=0$ until convergence, where $\Delta t$ is 212 some fictitious numerical time step:

$$
\frac{1}{\Delta t} \int_{\Omega}\left(T^{n}-T^{n-1}\right) S+\int_{\Omega} \kappa \nabla T^{n} \cdot \nabla S+\int_{\Omega}\left(\vec{u} \cdot \nabla T^{n}\right) S-\int_{\Omega} Q S=0 \forall S \in V_{h}
$$

213 Given the units we use, we observe that it is sufficient to make the order of 15 iterations with a 214 time step of 10 myrs corresponding to 150 myrs in total in order to reach a steady state.

215 In order to compute the heat transport field $\vec{u}$, we consider zero velocity in the continental crust 216 and we impose a rigid and constant movement along the parallel shape lines of the incoming plate.

217 We model the fluxes produced in the mantle wedge using a divergence free Stokes flux, 218 considering both momentum and mass conservation:

$$
\begin{gathered}
-v_{A} \Delta \vec{u}+\nabla \mathrm{p}=0 \\
\nabla \cdot \vec{u}=0
\end{gathered}
$$

219 in the region $\Omega_{A}$ occupied by the mantle wedge, where $\vec{u}=\left(u_{\mathrm{x}}, u_{\mathrm{y}}\right)$ and $\mathrm{p}$ are the velocity and 220 pressure of the fluid flow and $v_{A}$ is the kinematic viscosity of the asthenosphere in the wedge 221 mantle. Thus, only for the wedge mantle, the velocity field $\vec{u}=\left(u_{\mathrm{x}}, u_{\mathrm{y}}\right)$ is computed from the 
222 Stokes's variational formulation using finite elements of type P1b for the velocity (space $U_{h}$ ) and

223 P1 for the pressure (space $P_{h}$ ) by solving:

$$
\begin{aligned}
v_{A} \int_{\Omega_{A}} \frac{\partial u_{x}}{\partial x} \frac{\partial v_{x}}{\partial x} & +\frac{\partial u_{x}}{\partial y} \frac{\partial v_{x}}{\partial y}+\frac{\partial u_{y}}{\partial x} \frac{\partial v_{y}}{\partial x}+\frac{\partial u_{y}}{\partial y} \frac{\partial v_{y}}{\partial y} \\
& +\int_{\Omega_{A}} \frac{\partial p}{\partial x} v_{x}+\frac{\partial p}{\partial y} v_{y}+q\left(\frac{\partial u_{x}}{\partial x}+\frac{\partial u_{y}}{\partial y}\right)=0 \forall \vec{v} \in U_{h}, q \in P_{h}
\end{aligned}
$$

\subsubsection{Thermal Model Description (Boundary Conditions)}

225 For the heat equation, we consider that the temperature on the edge condition of the 226 incoming/subducting plate increases in deep $y$ by:

$$
T(y)=T_{S}+\left(T_{m}-T_{S}\right) \operatorname{erf}\left(\frac{y}{\sqrt{4 \kappa t}}\right)
$$

227 where $T_{S}=0$ and $T_{m}=1350^{\circ} \mathrm{C}$ are the surface and mantle temperatures, where erf is the Gaussian

228 error function, $t$ is the age of the plate $(50 \mathrm{myrs})$ and $\kappa$ is the thermal diffusivity of the incoming 229 plate. This is a good approximation for deep temperature profiles for low aged plates that is the 230 case for the entire Chilean trench (see Stein \& Stein, 1992; Vöelker et al., 2011). For the other 231 boundary conditions (Figure 4), we assume that $T$ varies quadratically from $1350^{\circ}$ to $1400{ }^{\circ} \mathrm{C}$ in 232 interior of the right boundary of the mantle wedge, $T=0$ at the surface, $T=1350{ }^{\circ} \mathrm{C}$ at the bottom 233 part of the subducting lithosphere and zero heat flux in the rest of the boundaries.

234 For the Stokes's equation, we take $\vec{u}=0$ in the continental crust and $\vec{u}=u_{0} \vec{\tau}(y)$ in the subducting 235 lithosphere where $u_{0}=67 \mathrm{~mm} / \mathrm{yr}$ is the imposed constant speed of the incoming plate with $\vec{\tau}(y)$ the 236 unit tangent vector to the subducting lithosphere shape lines depending on depth $y$. The boundary 237 conditions for the flow in the mantle wedge are $\vec{u}=0$ on the upper part of the wedge, $\vec{u}=u_{0} \vec{\tau}(y)$ 238 on the lower part of the wedge and free flow in the right edge of the wedge. See Text S1 in the 
supplementary information for more details.

\subsubsection{Thermal Model Description (Parameter Selection)}

241 Topography and bathymetry are taken from published data (Ryan et al., 2009). The geometry of

242 the subducted lithosphere is taken from Slab2.0 (Hayes et al., 2018). In addition, to assess our

243 model, we consider three different upper continental mantle depths of 60,80 and $100 \mathrm{~km}$.

244 However, as they show roughly similar results for the location of the mainshocks, we consider the 245 more realistic model of $60 \mathrm{~km}$ (Wada and Wang, 2009). Figures S16 and S17 show models with 24680 and $100 \mathrm{~km}$, respectively). A detail list of the other parameters used to develop the two247 dimensional model through finite element are listed in Table S5 where values are taken from 248 several authors (Hyndman \& Wang, 1993; Herzberg et al., 2007; Wang et al., 1995; Oleskevich et

249 al., 1999; Vöelker et al., 2011, Höink et al., 2011) for rheologic and geometric values. Please note 250 that heat diffusivity takes different values in three different regions: the subduction lithosphere, 251 the upper part of the continental crust and sediments and the rest of the domain. For the sources of 252 temperature, we also consider different radiative sources in the upper and lower continental crust 253 and sediments.

\subsection{Thermal Conditions of the Slab}

255 From our results of the slab thermal-conditions in northern Chile (Figure 3d), we observe that E1 256 and its aftershocks occurs near the $400{ }^{\circ} \mathrm{C}$ isotherm-depth and does not exceed the $450{ }^{\circ} \mathrm{C}$

257 isotherm, while the rest of the events occurs around or below this isotherm. Figures $3 \mathrm{~b}$ and $3 \mathrm{c}$

258 illustrate the relationship between the temperature of the slab at which events occur, the distance 259 from the top of the slab and number of aftershocks, respectively. Our analysis clearly reveals an 260 inverse relationship between the number of aftershocks and temperature. It is important to 
261 highlight that E6, the deepest within the slab, occurs at the highest temperatures range between

$262700-800^{\circ} \mathrm{C}$, and is the only event that does not exhibit aftershocks.

2645 Seismic Source properties

\subsection{Seismic Source Kinematic Inversions}

266 Having observed a clear difference of aftershock productivity as function of depth, we now

267 attempt to resolve any difference in rupture properties. To obtain the slip distribution of each

268 mainshock, we perform kinematic inversions using near-field stations on hard rock (Leyton et

269 al., 2018) (Figure 1), including 19 strong-motion stations and one broad-band station (Figure

270 S17). Since it is not possible to distinguish the causative fault plane from aftershocks geometry,

271 we consider the two possible fault planes, according to moment tensors reported by the USGS

272 (Tables S3 and S4). We assume a finite-fault model with an a-priori elliptical-patch slip

273 distribution. This methodology has been successfully used by several authors (Madariaga and

274 Ruiz, 2016; Ruiz et al., 2019). We inverted seven parameters. Five of them, correspond to

275 geometrical characteristic: semi-axes $a$ and $b$ of the ellipse, the rotation angle of the ellipse $\alpha$

276 and the location $\left(x_{0}, y_{0}\right)$ of its center into the fault plane, and the other two parameters are

277 maximum slip $D_{\max }$ and rupture velocity $V_{r}$. From this inverted rupture model, we compute

278 dynamic parameters using circular crack approximation obtained averaging both axes of the

279 ellipse (Ruiz et al., 2019 and references there in). Strong motion and broad band records were

280 corrected for the instrumental response and linear trend, filtered using a causal Butterworth filter

281 with corner frequencies of 0.02 and $0.1 \mathrm{~Hz}$, and then integrated to displacement. It is important

282 to mention that the high corner frequency is controlled by our simple elliptical model and the 1- 
283 D velocity model (Husen et al., 1999) used to simulate the wave propagation from the source to

284 the receivers. The misfit between observed and synthetic records was computed using a L2 norm 285 starting from origin time up to $75 \mathrm{~s}$ later to avoid including surface waves, and considering both 286 possible rupture planes reported by the USGS (Tables S3 and S4).

\subsection{Kinematic Parameters}

288 Considering all six events, our results show similar geometries of rupture (Table 1), with an 289 approximately circular rupture ranging from $\sim 3.5$ to $\sim 5 \mathrm{~km}$.

290 Figure 5 shows an example of the kinematic inversion results, for event E1 considering NP1. The

291 observed and synthetic displacement waveforms show a good agreement, with a maximum value

292 about $0.4 \mathrm{~cm}$ for the East-West component in station A20P (waveforms for all events in

293 Supplementary Figures S1-S12). In addition, although there are differences in the misfit values

294 for each of the fault planes considered (Tables S3 and S4), these are small enough to give 295 preference to one or the other.

296 The estimated stress drop values vary between 7.5 MPa and 29.5 MPa (Table 1), which are high

297 compared with typical values for shallow earthquakes (Derode \& Campos, 2019), but similar to

298 others observed for IDEs in Chile (Ruiz \& Madariaga, 2011; Ruiz et al., 2019) and at global

299 scale (Poli \& Prieto, 2014; Prieto et al., 2012). Despite a variability of rupture parameters exists

300 (Table 1), we do not see any clear correlation between them and the depth of the events. We thus 
301 suggest that the analyzed events, while occurring under different thermal conditions, all have a

302 similar rupture physics.

\section{Discussion}

305 While co-seismic rupture properties do not vary with distance from the top of the slab, we 306 observe clear differences in the post-seismic activity pattern, with a decrease of the aftershocks

307 as the distance from the top of the slab and temperature increase $\left(700-800^{\circ} \mathrm{C}\right.$ isotherm-depths).

308 Difference in the number of aftershocks between E1 and the rest of events could be related to the

309 hypocenter-depth within the slab. E1 is located $\sim 7 \mathrm{~km}$ from top of slab, close to the oceanic

310 Moho (Figure 1b; Patzwahl et al., 1999; Ranero and Sallarès, 2004). In addition, E1 aftershocks

311 locations reported by the CSN delineate a potential pre-existing fault aligned and similar to those 312 extensional faults located in the outer-rise region (Figure S13). These tensional faults are likely 313 caused by plate bending, and could provide a pathway for fluid infiltration, producing hydration 314 into the crust and uppermost mantle (Boneh et al., 2019; Contreras-Reyes et al., 2008; Iyer et al., 315 2012). However, how deeply water can infiltrate is still under debate, since the buoyancy of 316 water (or equivalently, confining pressure) makes it difficult to bring water down even when 317 faulting is deep (Korenaga, 2017). By contrast, numeric models suggest that stress variation 318 induced by plate bending can produce sub-hydrostatic or even negative pressure gradients along 319 normal faults, favoring thus downward pumping of fluids (Faccenda et al., 2009). On the other 320 hand, previous studies in the DSZ of this region (Dorbath et al., 2008) observed that the upper 321 seismicity plane (USP) corresponding to oceanic crust, is characterized by intermediate $V_{p}(\sim 7.7$ $322 \mathrm{~km} / \mathrm{s}$ ) and low $\mathrm{V}_{\mathrm{p}} / \mathrm{V}_{\mathrm{s}}(1.67)$ values, concluding that the USP is related to fluid releases associated 
323 with metamorphic reactions occurring within jadeite-lawsonite blueschists. Similarly, it has been

324 observed that the USP has significantly larger b-values than the LSP (Florez \& Prieto, 2019),

325 suggesting an hydrated USP and a relatively dry lithospheric mantle, since previous observations

326 have shown that high b-values anomalies correlate well with regions where dehydration reactions

327 are expected (Wiemer \& Benoit, 1996) or with hydrated fracture zones (Schlaphorst et al., 2016).

328 Thus, this hydrated zone could lead to a greater occurrence of aftershocks.

329 Furthermore, we observe a dominant tensional stress regime, where mainshocks with normal

330 focal mechanism occur up to $\sim 40 \mathrm{~km}$ from the top of the slab (i.e., $700-800{ }^{\circ} \mathrm{C}$ isotherm). This

331 isotherm-depth interval is much deeper than the expected depth for this type of focal mechanism

332 compared to neutral plane of the stress field estimated by Seno \& Yamanaka, (1996), who show

333 that the transition from tensional to compressional of outer rise events occur at the $400^{\circ}-450{ }^{\circ} \mathrm{C}$

334 isotherm-depth. If this is correct, our results show that the plate bending becomes stronger during

335 subduction and is likely more predominant than the cyclic stresses associated to the seismic

336 coupling at the thrust zone at depths where IDEs occur (Seno \& Yamanaka, 1996). Furthermore,

337 seismic tomographic studies off south-central Chile (Contreras-Reyes et al., 2008) and off

338 Nicaragua (Lefeldt et al., 2009) show a reduction in the upper oceanic mantle velocities from the

339 oceanic Moho up to $400^{\circ}-450^{\circ} \mathrm{C}$ isotherm-depth. This lower bound has been interpreted as the

340 maximum potential depth for hydro-alteration within the upper part of the oceanic lithosphere,

341 where extensional stresses dominate, and fluids may not be able to penetrate any deeper than

342 neutral plane (Contreras-Reyes et al., 2008; Lefeldt et al., 2009; Faccenda et al., 2009). Another

343 proposed interpretation is that these seismic velocity anomalies could be related to small-crack

344 porosities, which can be produced by a mixture between thermal cracking and bending-related

345 faulting (Korenaga, 2017). As described above, our observations could suggest the existence of a 
346 deepening of the neutral plane from $400-450{ }^{\circ} \mathrm{C}$ to $700-800{ }^{\circ} \mathrm{C}$ isotherm-depths regardless of the 347 presence of deep-water percolation.

348 A remaining question is, what could be controlling this deepening of the neutral plane along-dip?

349 Northern Chile corresponds to the region where the oceanic Nazca plate is relatively old (Figure

350 1) and therefore colder and with a deep fragile-ductile system (Figure 6), with an age of $54 \mathrm{Ma}$

351 near the trench axis (Müller et al., 2008) and 58 Ma estimated for the area where the mainshocks

352 occur. A plausible mechanism for a deepening of the neutral plane along-dip in northern Chile

353 would be the increase in bending stresses due to a greater slab-pull associated to the relative old,

354 cold and heavier already subducted oceanic Nazca plate. In particular, in this segment of the

355 Chilean margin, the largest known IDE has been registered for the slab-pull Tarapacá $2005 \mathrm{Mw}$

3567.7 event (Peyrat et al., 2006; Legrand and Delouis, 2006; Kuge et al., 2010; Ruiz and

357 Madariaga, 2018). Moreover, the 1950 Ms 8.0 tensional event (Kausel \& Campos, 1992)

358 occurred a little further south, reflecting the tensional character of the stress field within the 359 subducting slab. We also note how the moment tensors in northern Chile DSZ show a downdip 360 extensive stress field throughout the seismically active area (Sippl et al., 2019), which may imply 361 that plate bending, and unbending forces are small compared to slab-pull forces. Another 362 mechanism previously proposed by Kita et al. (2010) to explain the difference in the location of 363 the neutral plane beneath Tohoku and Hokkaido in the northeastern Japan is related to 364 differences in the thermal structure between the two regions. They concluded that the thermal 365 age of the subducted lithosphere and the oblique component of convergence rate affect the 366 density of the mantle wedge. This process triggers buoyancy force variations exerted in the slab 367 affecting finally the stress field of the subducting slab. However, this mechanism should be more 
368 dominant along strike (thermal variations are more important in that direction) rather than in 369 along dip.

370 On the other hand, the occurrence of tensional events up to depths of $40 \mathrm{~km}$ as E6 is consistent

371 with the brittle region predicted by a yield strength envelope (YSE) for an oceanic lithosphere

372 under tensional stresses (Figure 6), which reaches depths of $40-42 \mathrm{~km}$ for olivine and dry olivine

373 mineralogy, and it decreases for wet conditions. Likewise, using high-precision relocations, a

374 DSZ south of Iquique $\left(21.5^{\circ} \mathrm{S}\right)$ is observed (Rietbrock \& Waldhauser, 2004), with

375 predominantly extensional faulting in both seismic layers, and a clear down-dip tensional regime

376 with T-axes oriented in slab-parallel directions (Rietbrock \& Waldhauser, 2004; Sippl et al.,

377 2019). The consistency between the strength envelope and the maximum depths of intraplate

378 tensional events suggests that these earthquakes have ruptured through the entire brittle part of

379 the oceanic lithosphere. Another interesting observation is that events E5 and E6 highlight for its

380 isotherm-depth occurrence, about $700-800{ }^{\circ} \mathrm{C}$, which are higher than the stability limit of

381 antigorite at $600-650{ }^{\circ} \mathrm{C}$ commonly proposed as a lower limit for the LSP. As observed by Sippl

382 et al. $(2018 ; 2019)$ these events are more common in the Northern Chile DSZ, and a runaway-

383 type process could be responsible, under specific conditions in the lower plate (e.g. composition,

384 hydration, stress state). Likewise, according to McKenzie et al. (2005) particularly large strain

385 rates could also lead to earthquakes in regions below the $600-650{ }^{\circ} \mathrm{C}$ isotherm-depth. In our

386 study region, this could be related to an increase in the slab pull. Finally, thermal cracking

387 hypothesis (Korenaga, 2017) could also play a role, since the deepest hydrated cracks could be

388 more widely spaced than the most superficial cracks

389 Considering previous observations and our own results, we propose a conceptual model shown in

390 Figure 7, where the processes that occur are as follows: (1) in the outer-rise region extensional 
391 bend-faulting occur and lead to partial hydration of the crust and upper mantle. However, fluids

392 may not be able to penetrate any deeper than neutral plane (approximately $450{ }^{\circ} \mathrm{C}$ isotherm-

393 depth). Thus, the neutral plane separates a high-hydrated from a dry or poorly hydrated zones.

394 (2) As the oceanic plate subducts, a deepening of the neutral plane occurs by the increase of the

395 slab-pull forces, separating it from the $450{ }^{\circ} \mathrm{C}$ isotherm, and increasing the region subject to

396 extensional failure. (3) Normal (tensional) events occur at different distances from the top of the

397 slab, but their behavior is mostly controlled by variable physical background conditions. In

398 particular, in the high-hydrated region a greater number of aftershocks is observed, differently

399 from what is observed in the dry deeper zone.

\section{Conclusions}

402 We presented a detailed study of seismic source and aftershock productivity for the six largest

403 IDEs occurred in northern in Chile since 2010 and recorded by dense seismic arrays in the near-

404 field. Our results show that, although all of these events are located at different depths and under

405 different thermal conditions, all have similar rupture physics, with analogous geometries

406 considering an elliptical-patch approach and stress drop values between $7 \mathrm{MPa}$ and $30 \mathrm{MPa}$. On

407 the other hand, a clear decrease of the number of aftershocks as the distance from the top of the

408 slab and temperature increase is observed. We propose that this behavior could be controlled by

409 the incoming plate hydration, where the $400-450{ }^{\circ} \mathrm{C}$ isotherm-depths and neutral plane of the

410 stress field acts as limits for hydration in the outer-rise region, which is deepened by the slab-pull

411 as the slab subducts. 


\section{Declaration of competing interest}

414 The authors declare that they have no known competing financial interests or personal

415 relationships that could have appeared to influence the work reported in this paper.

416

\section{Acknowledgments}

418 We thank the Incorporated Research Institutions for Seismology Data Management Center and

419 Centro Sismológico Nacional who provided the raw data used in this work. LC thanks the

420 scholarship PFCHA/MagísterNacional/2018-22189566, granted by CONICYT. SR and ECR

421 thank the support of Chilean Fondo Nacional de Desarrollo Científico y Tecnológico

422 (FONDECYT), Grants 1170430 and 1170009, respectively. PP and LC were supported by the

423 European Union Horizon 2020 Research and Innovation Programme (grant agreements, 802777-

424 MONIFAULTS). AO acknowledges FONDECYT Grants 1191903 and 1201311, Basal CMM

425 ANIF PIA AFB170001 and Fondap CR2 Grant 15110009. We also acknowledge the support of

426 CONICYT PIA/Anillo de Investigación en Ciencia y Tecnología ACT172002. We also thank the

427 editor Eiichi Fukuyama, Jun Korenaga and another anonymous reviewer for their comments,

428 which improved the manuscript. We used Generic Mapping Tools 6 software for preparing some 429 plots. 


\section{References}

432 Barrientos, S., \& National Seismological Center (CSN) Team. (2018). The seismic network of

433 Chile. Seismological Research Letters, 89(2A), 467-474.

434 Beck, S. L., Zandt, G., \& Wagner, L. (2010). Central Andean uplift and the geodynamics of the

435 high topography. Other/Seismic Network, International Federation of Digital Seismograph

436 Networks.

437 Boneh, Y., Schottenfels, E., Kwong, K., van Zelst, I., Tong, X., Eimer, M., Miller, M., Moresi,

438 L., Warren, J., Wiens, D., Billen, M., Naliboff, J., \& Zhan, Z. (2019). Intermediate-depth

439 earthquakes controlled by incoming plate hydration along bending-related faults. Geophysical

$440 \quad$ Research Letters, 46(7), 3688-3697.

441 Comte, D., Dorbath, L., Pardo, M., Monfret, T., Haessler, H., Rivera, L., Frogneux, M., Glass,

442 B., \& Meneses, C. (1999). A double-layered seismic zone in Arica, northern Chile. Geophysical

443 Research Letters, 26(13), 1965-1968.

444 Contreras-Reyes, E., Grevemeyer, I., Flueh, E. R., \& Reichert, C. (2008). Upper lithospheric

445 structure of the subduction zone offshore of southern Arauco peninsula, Chile, at 38 S. Journal

446 of Geophysical Research: Solid Earth, 113(B7).

447 Contreras-Reyes, E., \& Osses, A. (2010). Lithospheric flexure modelling seaward of the Chile

448 trench: implications for oceanic plate weakening in the Trench Outer Rise region. Geophysical

449 Journal International, 182(1), 97-112.

450 Contreras-Reyes, E, J. Jara, I. Grevemeyer, S. Ruiz, and D. Carrizo (2012). Abrupt change in the 451 dip of the subducting plate beneath north Chile. Nature Geoscience, 5, 342-345. 
453 Contreras-Reyes, E. (2018). Structure and tectonics of the Chilean convergent margin from

454 wide-angle seismic studies: a review. In The Evolution of the Chilean-Argentinean Andes (pp. 3455 29). Springer, Cham.

456 Dascher-Cousineau, K., Brodsky, E., Lay, T., \& Goebel, T. (2020). What controls variations in 457 aftershock productivity?. Geophysical Research Letters.

458 Delouis, B., \& Legrand, D. (2007). Mw 7.8 Tarapaca intermediate depth earthquake of 13 June 4592005 (northern Chile): Fault plane identification and slip distribution by waveform inversion. 460 Geophysical Research Letters, 34(1).

461 DeMets, C., Gordon, R. G., \& Argus, D. F. (2010). Geologically current plate motions. 462 Geophysical Journal International, 181(1), 1-80.

463 Derode, B., \& Campos, J. (2019). Energy Budget of Intermediate-Depth Earthquakes in Northern 464 Chile: Comparison With Shallow Earthquakes and Implications of Rupture Velocity Models 465 Used. Geophysical Research Letters, 46(5), 2484-2493.

466 Dorbath, C., Gerbault, M., Carlier, G., \& Guiraud, M. (2008). Double seismic zone of the Nazca 467 plate in northern Chile: High-resolution velocity structure, petrological implications, and 468 thermomechanical modeling. Geochemistry, Geophysics, Geosystems, 9(7).

469 Ferrand, T. P., Hilairet, N., Incel, S., Deldicque, D., Labrousse, L., Gasc, J., Renner, J., Wang, 470 Y., Green, H., \& Schubnel, A. (2017). Dehydration-driven stress transfer triggers intermediate471 depth earthquakes. Nature communications, 8(1), 1-11.

472 Frank, W. B., Poli, P., \& Perfettini, H. (2017). Mapping the rheology of the Central Chile 473 subduction zone with aftershocks. Geophysical Research Letters, 44(11), 5374-5382. 
474 Florez, M. A., \& Prieto, G. A. (2019). Controlling factors of seismicity and geometry in double 475 seismic zones. Geophysical Research Letters, 46(8), 4174-4181.

476 Frohlich, C. (1987). Aftershocks and temporal clustering of deep earthquakes. Journal of 477 Geophysical Research: Solid Earth, 92(B13), 13944-13956.

478 Frohlich, C. (2006). Deep earthquakes. Cambridge university press.

479 Geersen, J., Ranero, C. R., Klaucke, I., Behrmann, J. H., Kopp, H., Tréhu, A. M., Contreras480 Reyes, E., Barckhausen, U. \& Reichert, C. (2018). Active tectonics of the North Chilean marine 481 forearc and adjacent oceanic Nazca Plate. Tectonics, 37(11), 4194-4211.

482 GFZ German Research Centre for Geosciences; Institut des Sciences de 1'Univers-Centre 483 National de la Recherche CNRS-INSU (2006): IPOC Seismic Network. Integrated Plate 484 boundary Observatory Chile - IPOC. Other/Seismic Network. doi.org/10.14470/PK615318. 485 Goetze, C. (1978). The mechanisms of creep in olivine. Philosophical Transactions of the Royal 486 Society of London. Series A, Mathematical and Physical Sciences, 288(1350), 99-119.

487 Hacker, B. R., Peacock, S. M., Abers, G. A., \& Holloway, S. D. (2003). Subduction factory 2. 488 Are intermediate-depth earthquakes in subducting slabs linked to metamorphic dehydration 489 reactions?. Journal of Geophysical Research: Solid Earth, 108(B1).

490 Hainzl, S., Sippl, C., \& Schurr, B. (2019). Linear relationship between aftershock productivity 491 and seismic coupling in the Northern Chile subduction zone. Journal of Geophysical Research: 492 Solid Earth, 124(8), 8726-8738.

493 Hayes, G. P., Moore, G. L., Portner, D. E., Hearne, M., Flamme, H., Furtney, M., \& Smoczyk, 494 G. M. (2018). Slab2, a comprehensive subduction zone geometry model. Science, 362(6410), 5849561. 
496 Herzberg, C., Asimow, P. D., Arndt, N., Niu, Y., Lesher, C. M., Fitton, J. G., ... \& Saunders, A. 497 D. (2007). Temperatures in ambient mantle and plumes: Constraints from basalts, picrites, and 498 komatiites. Geochemistry, Geophysics, Geosystems, 8(2).

499 Höink, T., Jellinek, A. M., and Lenardic, A. (2011), Viscous coupling at the lithosphere500 asthenosphere boundary, Geochem. Geophys. Geosyst., 12.

501 Houston, H. (2015). Deep earthquakes. Elsevier.

502 Husen, S., Kissling, E., Flueh, E., \& Asch, G. (1999). Accurate hypocenter determination in the 503 shallow part of the Nazca subduction zone in Northern Chile using a combined on-/offshore 504 network. Geophysical Journal International, 138, 687-701.

505 Hyndman, R. D., \& Wang, K. (1993). Thermal constraints on the zone of major thrust 506 earthquake failure: The Cascadia subduction zone. Journal of Geophysical Research: Solid 507 Earth, 98(B2), 2039-2060.

508 Iyer, K., Rüpke, L. H., Phipps Morgan, J., \& Grevemeyer, I. (2012). Controls of faulting and 509 reaction kinetics on serpentinization and double Benioff zones. Geochemistry, Geophysics, 510 Geosystems, 13(9).

511 John, T., Medvedev, S., Rüpke, L. H., Andersen, T. B., Podladchikov, Y. Y., \& Austrheim, H. 512 (2009). Generation of intermediate-depth earthquakes by self-localizing thermal runaway.

$513 \quad$ Nature Geoscience, 2(2), 137-140.

514 Jung, H., Green Ii, H. W., \& Dobrzhinetskaya, L. F. (2004). Intermediate-depth earthquake 515 faulting by dehydration embrittlement with negative volume change. Nature, 428(6982), 545516549. 
517 Kausel, E., \& Campos, J. (1992). The Ms= 8 tensional earthquake of 9 December 1950 of 518 northern Chile and its relation to the seismic potential of the region. Physics of the earth and 519 planetary interiors, 72(3-4), 220-235.

520 Karato, S. I., Paterson, M. S., \& FitzGerald, J. D. (1986). Rheology of synthetic olivine

521 aggregates: influence of grain size and water. Journal of Geophysical Research: Solid Earth, 522 91(B8), 8151-8176.

523 Khazaradze, G., \& Klotz, J. (2003). Short-and long-term effects of GPS measured crustal 524 deformation rates along the south central Andes. Journal of Geophysical Research: Solid Earth, $525108(\mathrm{~B} 6)$.

526 Kirby, S. H., Durham, W. B., \& Stern, L. A. (1991). Mantle phase changes and deep-earthquake 527 faulting in subducting lithosphere. Science, 252(5003), 216-225.

528 Kirby, S. (1995). Interslab earthquakes and phase changes in subducting lithosphere. Reviews of 529 Geophysics, 33(S1), 287-297.

530 Kita, S., Okada, T., Hasegawa, A., Nakajima, J., \& Matsuzawa, T. (2010). Existence of 531 interplane earthquakes and neutral stress boundary between the upper and lower planes of the 532 double seismic zone beneath Tohoku and Hokkaido, northeastern Japan. Tectonophysics, 496(1$5334), 68-82$.

534 Kohlstedt, D. L., Evans, B., \& Mackwell, S. J. (1995). Strength of the lithosphere: Constraints 535 imposed by laboratory experiments. Journal of Geophysical Research: Solid Earth, 100(B9), $536 \quad 17587-17602$.

537 Korenaga, J. (2017). On the extent of mantle hydration caused by plate bending. Earth and 538 Planetary Science Letters, 457, 1-9. 
539 Kuge, K., Kase, Y., Urata, Y., Campos, J., \& Perez, A. (2010). Rupture characteristics of the

5402005 Tarapaca, northern Chile, intermediate-depth earthquake: Evidence for heterogeneous fluid

541 distribution across the subducting oceanic plate?. Journal of Geophysical Research: Solid Earth,

$542115(\mathrm{~B} 9)$.

543 Kukowski, N., \& Oncken, O. (2006). Subduction erosion-The "normal" mode of fore-arc

544 material transfer along the Chilean margin?. In The Andes (pp. 217-236). Springer, Berlin, 545 Heidelberg.

546 Leyton, F., Leopold, A., Hurtado, G., Pastén, C., Ruiz, S., Montalva, G., \& Saez, E. (2018).

547 Geophysical characterization of the Chilean seismological stations: First results. Seismological

548 Research Letters, 89(2A), 519-525.

549 Lefeldt, M., Grevemeyer, I., Goßler, J., \& Bialas, J. (2009). Intraplate seismicity and related 550 mantle hydration at the Nicaraguan trench outer rise. Geophysical Journal International, 178(2), $551 \quad 742-752$.

552 Li, C., Peng, Z., Yao, D., Guo, H., Zhan, Z., \& Zhang, H. (2018). Abundant aftershock sequence 553 of the $2015 \mathrm{M}$ w7. 5 Hindu Kush intermediate-depth earthquake. Geophysical Journal 554 International, 213(2), 1121-1134.

555 Madariaga, R., and S. Ruiz (2016). Earthquake dynamics on circular faults: A review 1970556 2015, J. Seismol. 20, 1235-1252, doi: 10.1007/s10950-016-9590-8.

557 Maksymowicz, A., \& Tassara, A. (2018). The Geometry of the Continental Wedge and Its 558 Relation to the Rheology and Seismicity of the Chilean Interplate Boundary. In The Evolution of 559 the Chilean-Argentinean Andes (pp. 31-58). Springer, Cham. 
560 McKenzie, D., Jackson, J., \& Priestley, K. (2005). Thermal structure of oceanic and continental

561 lithosphere. Earth and Planetary Science Letters, 233(3-4), 337-349.

562 Müller, R. D., Sdrolias, M., Gaina, C., \& Roest, W. R. (2008). Age, spreading rates, and

563 spreading asymmetry of the world's ocean crust. Geochemistry, Geophysics, Geosystems, 9(4).

564 Ohuchi, T., Lei, X., Ohfuji, H., Higo, Y., Tange, Y., Sakai, T., Fujino, K., \& Irifune, T. (2017).

565 Intermediate-depth earthquakes linked to localized heating in dunite and harzburgite. Nature 566 Geoscience, 10(10), 771-776.

567 Oleskevich, D. A., Hyndman, R. D., \& Wang, K. (1999). The updip and downdip limits to great 568 subduction earthquakes: Thermal and structural models of Cascadia, south Alaska, SW Japan, 569 and Chile. Journal of Geophysical Research: Solid Earth, 104(B7), 14965-14991.

570 Patzwahl, R., Mechie, J., Schulze, A., \& Giese, P. (1999). Two-dimensional velocity models of 571 the Nazca plate subduction zone between $19.5^{\circ} \mathrm{S}$ and $25^{\circ} \mathrm{S}$ from wide-angle seismic 572 measurements during the CINCA95 project. Journal of Geophysical Research: Solid Earth, 573 104(B4), 7293-7317.

574 Peacock, S. M. (2001). Are the lower planes of double seismic zones caused by serpentine 575 dehydration in subducting oceanic mantle?. Geology, 29(4), 299-302.

576 Peng, Z., \& Zhao, P. (2009). Migration of early aftershocks following the 2004 Parkfield 577 earthquake. Nature Geoscience, 2(12), 877-881.

578 Persh, S. E., \& Houston, H. (2004). Strongly depth-dependent aftershock production in deep 579 earthquakes. Bulletin of the Seismological Society of America, 94(5), 1808-1816.

580 Peyrat, S., Campos, J., De Chabalier, J. B., Perez, A., Bonvalot, S., Bouin, M. P., Legrand, D., 581 Nercessian, A., Charade, O., Patau, G., Clévédé, E., Kausel, E., Bernard, P. \& Vilotte, J.-P. 
582 (2006). Tarapacá intermediate-depth earthquake (Mw 7.7, 2005, northern Chile): A slab-pull

583 event with horizontal fault plane constrained from seismologic and geodetic observations.

584 Geophysical Research Letters, 33(22).

585 Poli, P., \& Prieto, G. (2014). Global and along-strike variations of source duration and scaling

586 for intermediate-depth and deep-focus earthquakes. Geophysical Research Letters, 41(23), 8315-

5878324.

588 Poli, P., Prieto, G., Rivera, E., \& Ruiz, S. (2016). Earthquakes initiation and thermal shear

589 instability in the Hindu Kush intermediate depth nest. Geophysical Research Letters, 43(4),

$590 \quad 1537-1542$.

591 Prieto, G. A., Beroza, G. C., Barrett, S. A., López, G. A., \& Florez, M. (2012). Earthquake nests

592 as natural laboratories for the study of intermediate-depth earthquake mechanics.

593 Tectonophysics, 570, 42-56.

594 Ranero, C. R., \& Sallarès, V. (2004). Geophysical evidence for hydration of the crust and mantle 595 of the Nazca plate during bending at the north Chile trench. Geology, 32(7), 549-552.

596 Ranero, C. R., Villaseñor, A., Phipps Morgan, J., \& Weinrebe, W. (2005). Relationship between

597 bend-faulting at trenches and intermediate-depth seismicity. Geochemistry, Geophysics,

598 Geosystems, 6(12).

599 Reynard, B., Nakajima, J., \& Kawakatsu, H. (2010). Earthquakes and plastic deformation of 600 anhydrous slab mantle in double Wadati-Benioff zones. Geophysical Research Letters, 37(24).

601 Richardson, E., \& Jordan, T. H. (2002). Low-frequency properties of intermediate-focus

602 earthquakes. Bulletin of the Seismological Society of America, 92(6), 2434-2448. 
603 Rietbrock, A., \& Waldhauser, F. (2004). A narrowly spaced double-seismic zone in the 604 subducting Nazca plate. Geophysical Research Letters, 31(10).

605 Ruiz, S., \& Madariaga, R. (2011). Determination of the friction law parameters of the Mw 6.7

606 Michilla earthquake in northern Chile by dynamic inversion. Geophysical Research Letters, $60738(9)$.

608 Ruiz, S., and R. Madariaga. "Historical and recent large megathrust earthquakes in Chile." 609 Tectonophysics 733 (2018): 37-56.

610 Ruiz, S., Ammirati, J. B., Leyton, F., Cabrera, L., Potin, B., \& Madariaga, R. (2019). The 611 January 2019 (M w 6.7) Coquimbo Earthquake: Insights from a Seismic Sequence within the 612 Nazca Plate. Seismological Research Letters, 90(5), 1836-1843.

613 Rutland, R. W. R. (1971). Andean orogeny and ocean floor spreading. Nature, 233(5317), 252614255.

615 Ryan, W. B., Carbotte, S. M., Coplan, J. O., O'Hara, S., Melkonian, A., Arko, R., Weissel, R. A., 616 Ferrini, V., Goodwillie, A., Nitsche, F., Bonczkowski, J. \& Zemsky, R. (2009). Global multi617 resolution topography synthesis. Geochemistry, Geophysics, Geosystems, 10(3).

618 Schlaphorst, D., Kendall, J. M., Collier, J. S., Verdon, J. P., Blundy, J., Baptie, B., Latchman, J., 619 Massin, F., \& Bouin, M. P. (2016). Water, oceanic fracture zones and the lubrication of 620 subducting plate boundaries - insights from seismicity. Geophysical Journal International, $621204(3), 1405-1420$.

622 Seno, T., \& Yamanaka, Y. (1996). Double seismic zones, compressional deep trench-outer rise 623 events, and superplumes. Subduction: top to bottom, 96, 347-355. 
624 Senobari, N. S., Funning, G. J., Keogh, E., Zhu, Y., Yeh, C. C. M., Zimmerman, Z., \& Mueen, 625 A. (2019). Super-Efficient Cross-Correlation (SEC-C): A Fast Matched Filtering Code Suitable 626 for Desktop Computers. Seismological Research Letters, 90(1), 322-334.

627 Shebalin, P., \& Narteau, C. (2017). Depth dependent stress revealed by aftershocks. Nature 628 communications, 8(1), 1-8.

629 Shelly, D. R., Beroza, G. C., \& Ide, S. (2007). Non-volcanic tremor and low-frequency 630 earthquake swarms. Nature, 446(7133), 305-307.

631 Sippl, C., Schurr, B., Asch, G., \& Kummerow, J. (2018). Seismicity structure of the northern 632 Chile forearc from>100,000 double-difference relocated hypocenters. Journal of Geophysical 633 Research: Solid Earth, 123(5), 4063-4087.

634 Sippl, C., Schurr, B., John, T., \& Hainzl, S. (2019). Filling the gap in a double seismic zone: 635 Intraslab seismicity in Northern Chile. Lithos, 346, 105155.

636 Stern, C. R. (2011). Subduction erosion: rates, mechanisms, and its role in arc magmatism and 637 the evolution of the continental crust and mantle. Gondwana Research, 20(2-3), 284-308.

638 Stein, C. A., \& Stein, S. (1992). A model for the global variation in oceanic depth and heat flow 639 with lithospheric age. Nature, 359(6391), 123-129.

640 Tassara, A., \& Echaurren, A. (2012). Anatomy of the Andean subduction zone: three641 dimensional density model upgraded and compared against global-scale models. Geophysical 642 Journal International, 189(1), 161-168.

643 Völker, D., Grevemeyer, I., Stipp, M., Wang, K., \& He, J. (2011). Thermal control of the 644 seismogenic zone of southern central Chile. Journal of Geophysical Research: Solid Earth, 645 116(B10). 
646 Wada, I., \& Wang, K. (2009). Common depth of slab-mantle decoupling: Reconciling diversity 647 and uniformity of subduction zones. Geochemistry, Geophysics, Geosystems, 10(10).

648 Wang, K., Hyndman, R. D., \& Yamano, M. (1995). Thermal regime of the Southwest Japan 649 subduction zone: effects of age history of the subducting plate. Tectonophysics, 248(1-2), 53-69.

650 Wessel, P., Luis, J. F., Uieda, L., Scharroo, R., Wobbe, F., Smith, W. H. F., \& Tian, D. (2019).

651 The generic mapping tools version 6. Geochemistry, Geophysics, Geosystems, 20(11), 55566525564.

653 Wiemer, S., \& Benoit, J. P. (1996). Mapping the b-value anomaly at $100 \mathrm{~km}$ depth in the Alaska 654 and New Zealand subduction zones. Geophysical Research Letters, 23(13), 1557-1560.

655 Wiens, D. A., McGuire, J. J., Shore, P. J., Bevis, M. G., Draunidalo, K., Prasad, G., \& Helu, S. P. 656 (1994). A deep earthquake aftershock sequence and implications for the rupture mechanism of 657 deep earthquakes. Nature, 372(6506), 540-543.

658 Wiens, D. A., \& Gilbert, H. J. (1996). Effect of slab temperature on deep-earthquake aftershock 659 productivity and magnitude-frequency relations. Nature, 384(6605), 153-156.

660 Wiens, D. A. (2001). Seismological constraints on the mechanism of deep earthquakes: 661 Temperature dependence of deep earthquake source properties. Physics of the Earth and 662 Planetary Interiors, 127(1-4), 145-163.

663 Zhan, Z., Helmberger, D. V., Kanamori, H., \& Shearer, P. M. (2014). Supershear rupture in a 664 Mw 6.7 aftershock of the 2013 Sea of Okhotsk earthquake. Science, 345(6193), 204-207. 665 
Table 1

667 Resume of kinematic parameters and number of aftershocks obtained for each mainshock.

\begin{tabular}{|c|c|c|c|c|c|c|c|}
\hline Event & $\begin{array}{c}a \\
(\boldsymbol{k m})\end{array}$ & $\begin{array}{c}\boldsymbol{b} \\
(\boldsymbol{k m})\end{array}$ & $\begin{array}{l}D_{\max } \\
(\boldsymbol{m})\end{array}$ & $\begin{array}{c}V_{r} \\
(k m / s)\end{array}$ & $\begin{array}{l}\text { Stress drop } \\
(\mathbf{M P a})\end{array}$ & $\begin{array}{l}\text { Number of } \\
\text { aftershocks }\end{array}$ & $\begin{array}{l}\text { Distance from the } \\
\text { top of the slab }(\mathrm{km})\end{array}$ \\
\hline \multirow{2}{*}{ E1 } & 3.49 & 5.13 & 1.08 & 1.07 & 18.2 & \multirow{2}{*}{2044} & \multirow{2}{*}{ 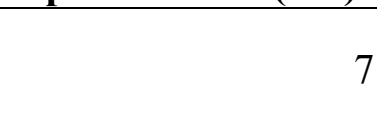 } \\
\hline & 3.67 & 5.68 & 0.94 & 1.19 & 14.7 & & \\
\hline \multirow{2}{*}{ E2 } & 4.38 & 6.99 & 0.65 & 1.59 & 8.5 & \multirow{2}{*}{123} & \multirow{2}{*}{12} \\
\hline & 4.12 & 6.58 & 0.73 & 1.51 & 9.9 & & \\
\hline \multirow{2}{*}{ E3 } & 5.05 & 6.16 & 1.12 & 0.67 & 14.3 & \multirow{2}{*}{30} & \multirow{2}{*}{14} \\
\hline & 4.14 & 6.44 & 1.24 & 0.82 & 16.7 & & \\
\hline \multirow{2}{*}{ E4 } & 4.70 & 3.90 & 0.73 & 1.22 & 12.8 & \multirow[b]{2}{*}{46} & \multirow[b]{2}{*}{20} \\
\hline & 4.56 & 5.60 & 0.52 & 1.91 & 7.5 & & \\
\hline \multirow{2}{*}{ E5 } & 5.89 & 4.25 & 0.71 & 1.68 & 10.0 & \multirow{2}{*}{16} & \multirow{2}{*}{38} \\
\hline & 4.88 & 6.11 & 0.60 & 2.20 & 8.1 & & \\
\hline \multirow{2}{*}{ E6 } & 3.12 & 4.42 & 1.61 & 0.68 & 29.5 & \multirow{2}{*}{0} & \multirow{2}{*}{41} \\
\hline & 3.43 & 6.40 & 0.95 & 0.80 & 14.1 & & \\
\hline
\end{tabular}



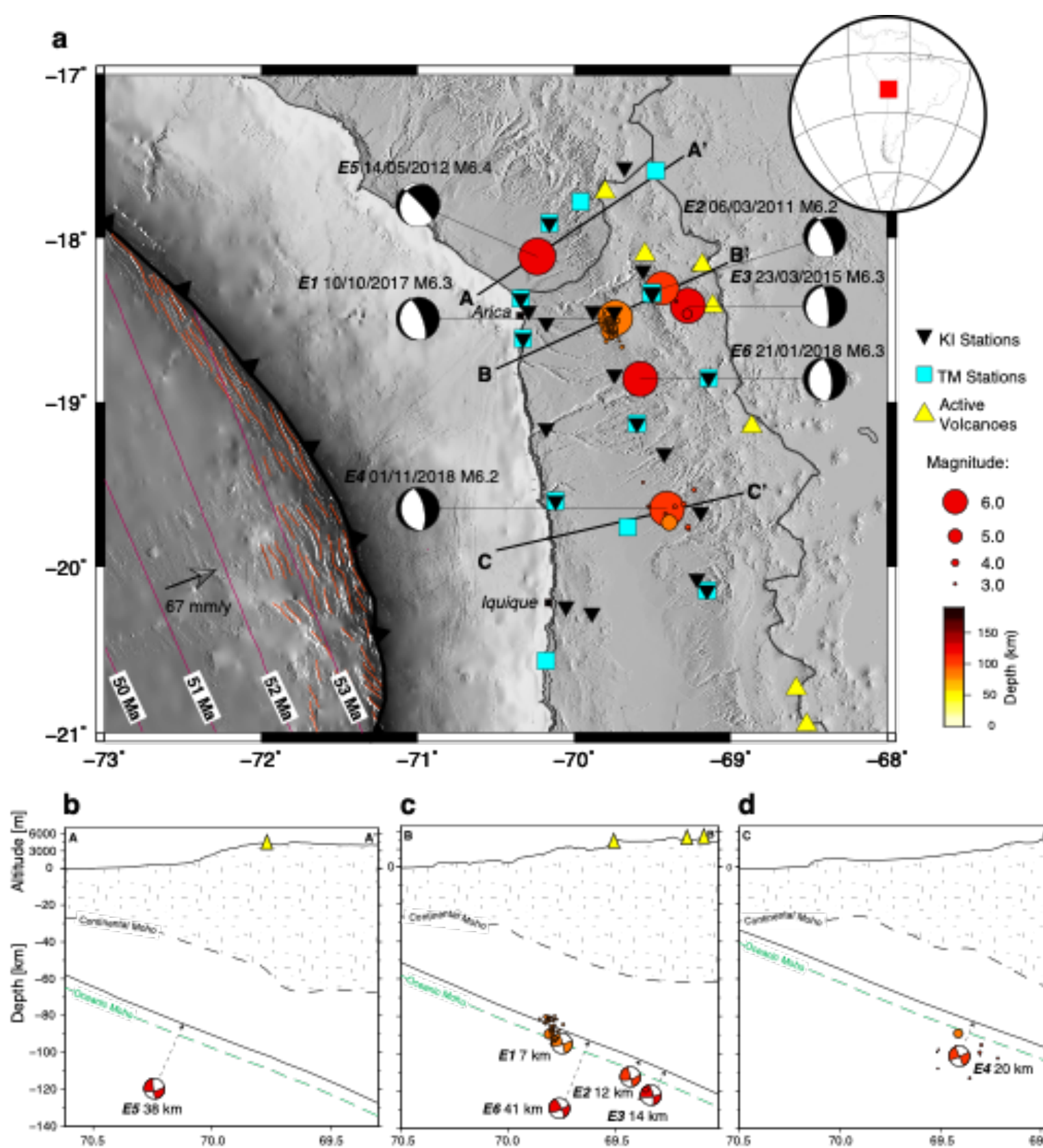

C

d

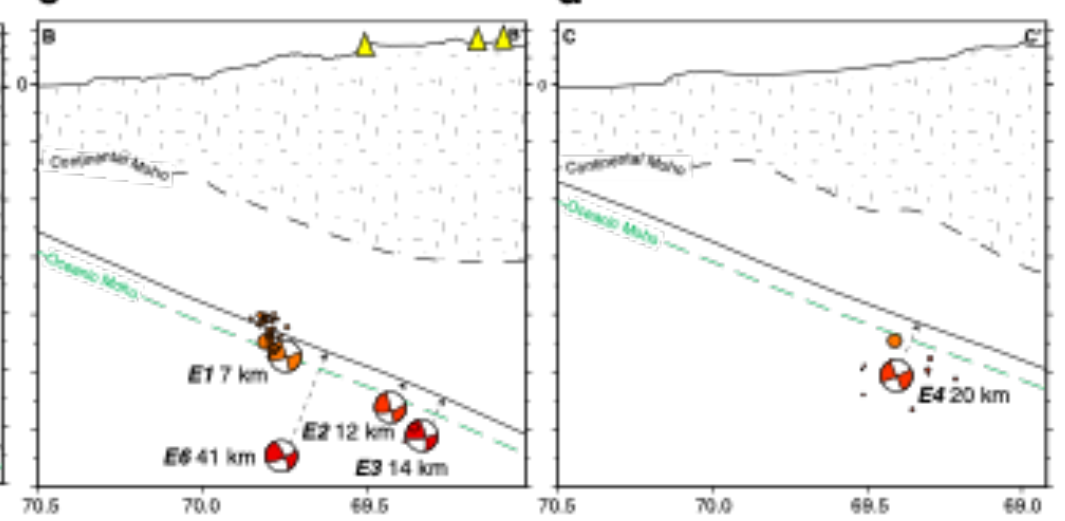

672 Figure 1. Seismotectonic setting of the northern Chile region. a Orange circles indicate the mainshocks (labeled as E1, E2 and so

673 on according to their distance from the top of the slab) and aftershocks epicenters (CSN catalogue), scaled and colored by

674 magnitude and depth. Focal mechanisms are obtained from USGS, and also date and magnitude according to CSN are indicated.

675 Black inverted triangles and cyan squares are the locations of the stations used for the kinematic inversions (KI) and template

676 matching (TM), respectively. Yellow triangles represent active volcanoes. Red lines indicate faulting located on the outer-rise

677 region. Isochrones for the Nazca plate (Müller et al., 2008) are indicated with magenta lines. (Inset) Global map with the 
678 specified study area. b, $\mathbf{c}$ and $\mathbf{d}$ cross sections along segments AA', BB' and CC' respectively in a. Distance from the top of the

679 slab is indicated for each mainshock. The slab (black solid line) corresponds to the projection along cross-sections of the Nazca

680 slab model SLAB2.0 (Hayes et al., 2018). Black and green dashed lines correspond to continental Moho (Tassara \& Echaurren,

681 2012) and oceanic Moho (Contreras-Reyes et al., 2012), respectively. 


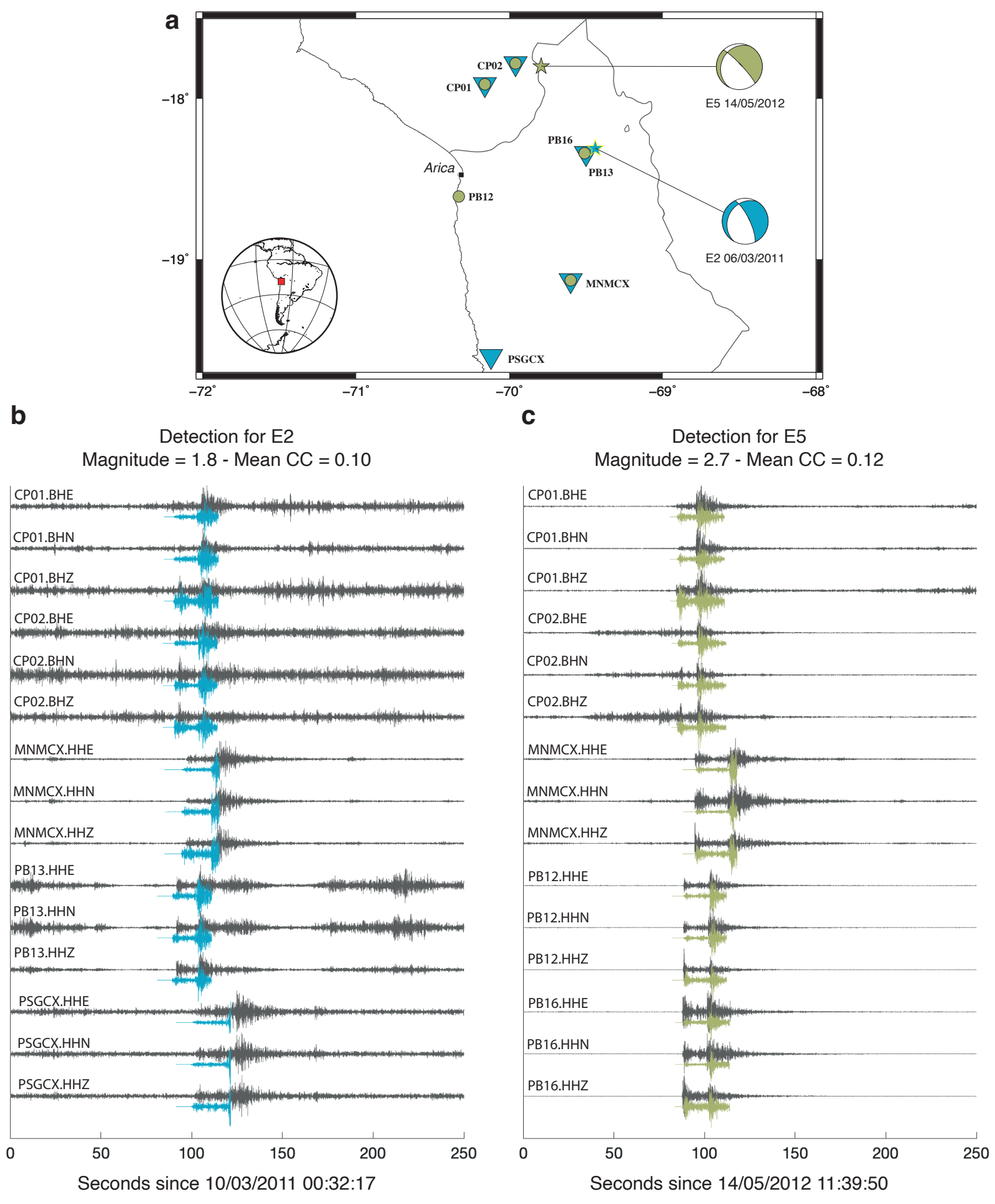

Figure 2. Example of new events detected using template matching. a Map of stations used for E2 (cyan inverted triangles) and E5 (green dots). Stars represent epicenter for each event (CSN), and their focal mechanism according to USGS are also plotted. (Inset) Global map with the specified study area. b Example of a new detection in the continuous data for E2. Cyan traces represent templates aligned considering their respective moveouts. The average correlation coefficient (Mean CC) is 0.10 and the inferred magnitude (Mw) 1.8. c Example of a new detection in the continuous data for E5. Green traces represent templates aligned considering their respective moveouts. The average correlation coefficient (Mean CC) is 0.12 and the inferred magnitude (Mw) for the new event is 2.7. 

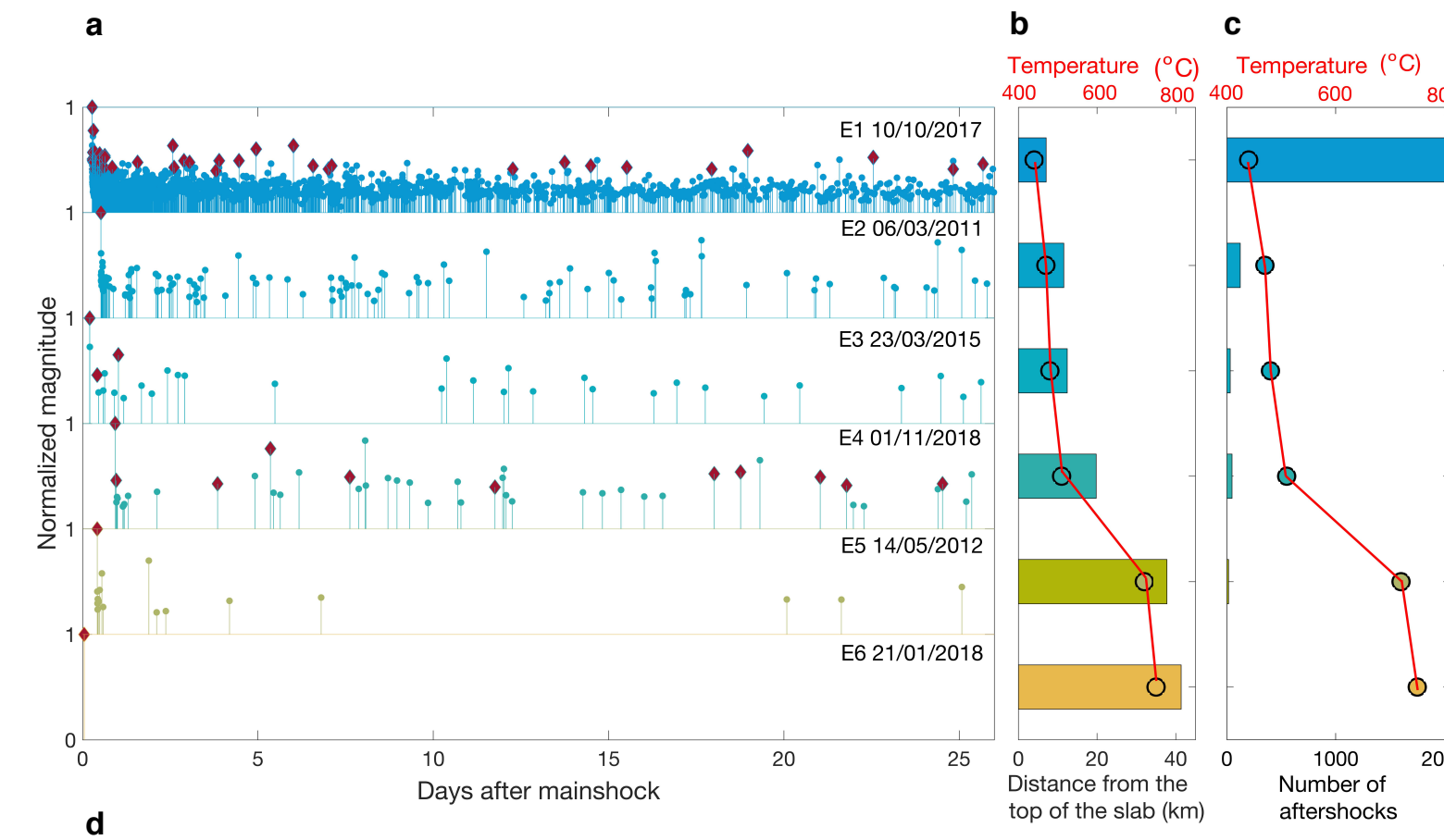

$\begin{array}{lllll}400 \quad 600 \quad 800 \quad 400 \quad 600 & 800\end{array}$
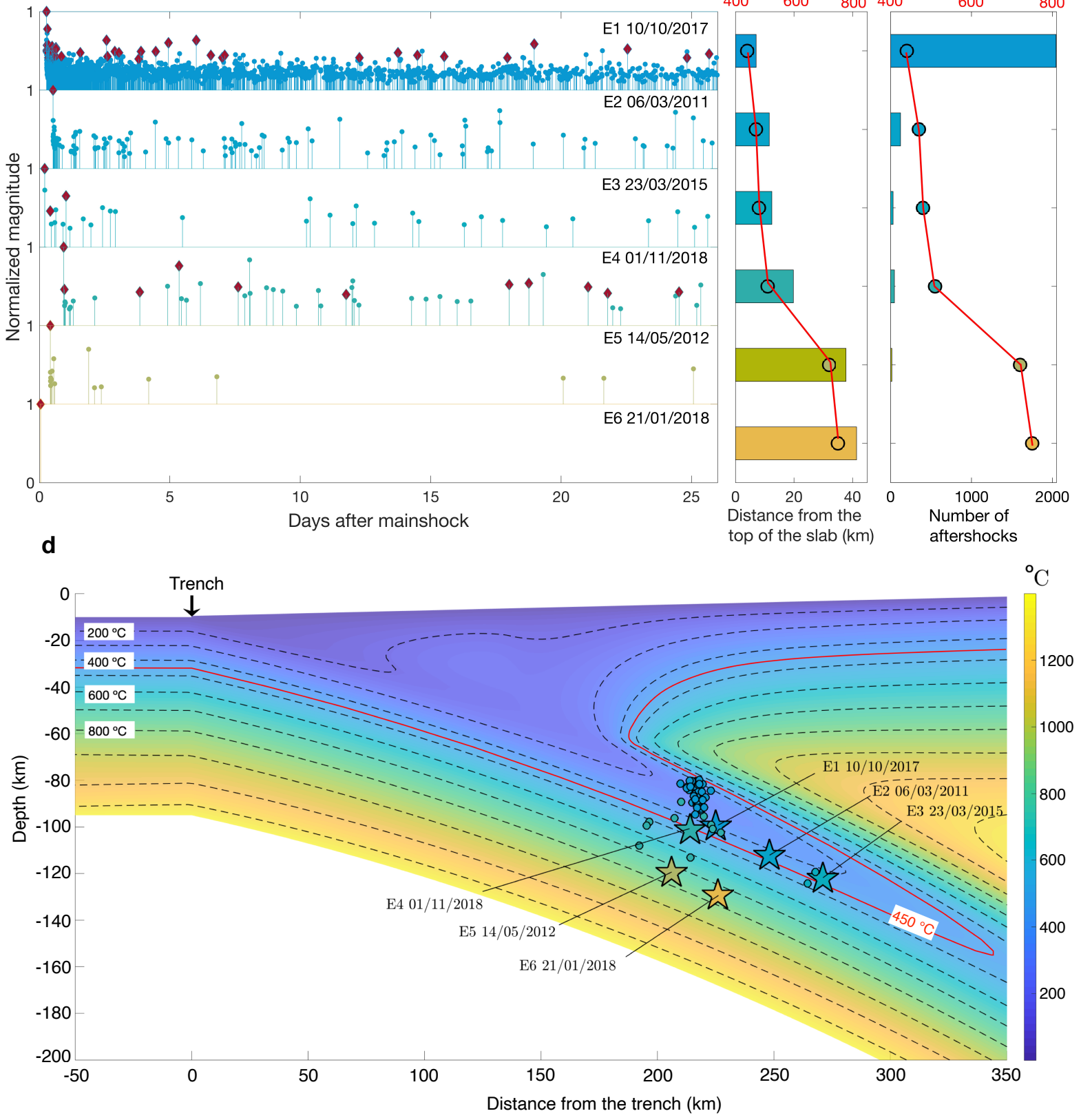

693 Figure 3. Results for aftershocks efficency and thermal model. a Detections using TM. For each row, stems show aftershocks detections until 25 days after mainshocks using TM as indicated in section 2.1. Stem height is normalized by the mainshock magnitude,and templates used are indicated as magenta diamonds. b Distance from the top of slab (Figure 1) is indicated with horizontal bars, and red line shows estimated temperature for hypocenter location according to the thermal model in $\mathbf{d}$. $\mathbf{c}$ Horizontal bars indicate total number of aftershocks and red line the temperature. $\mathbf{d}$ Thermal model for northern Chile. 
(C1)

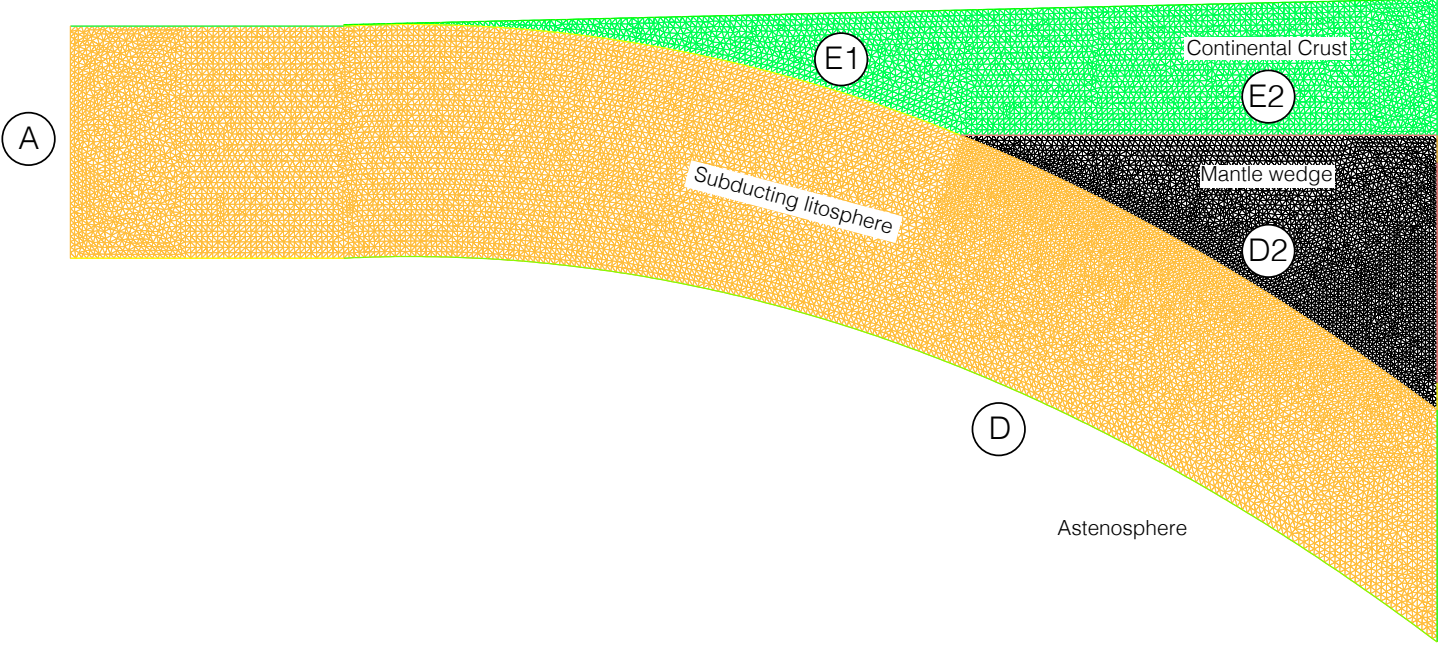

Figure 4. FEM grid and boundary conditions used for thermal numerical modelling. Continental crust, mantle wedge and oceanic 


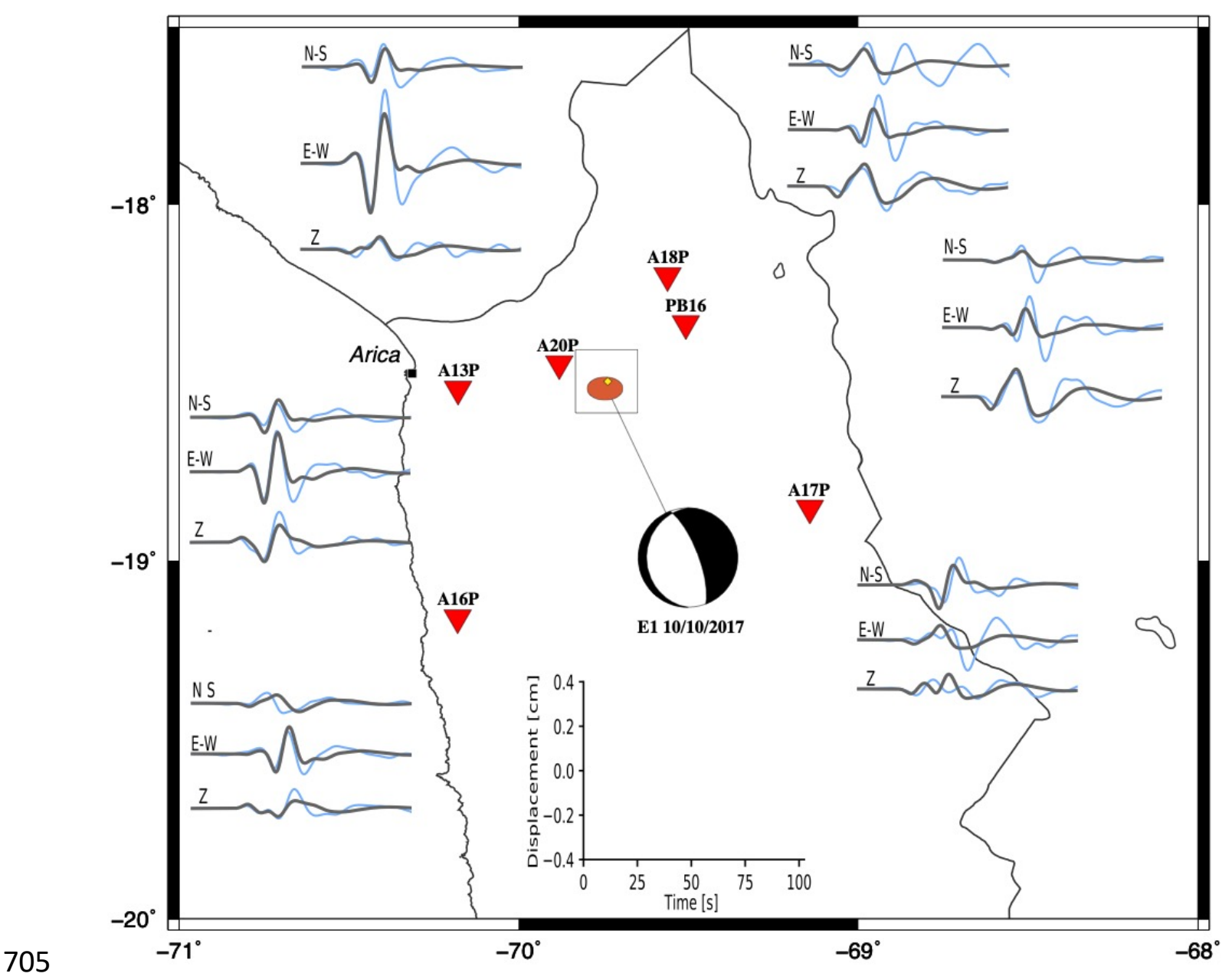

Figure 5. Example of kinematic inversion for E1. Ellipse shows the rupture area of the mainshock, with at maximum slip amplitude of $1.08 \mathrm{~m}$. Yellow diamond is the National Seismological Center (CSN) mainshock epicenter. Inverted red triangles are near-field stations considered for inversion. Gray and blue lines are simulated and observed displacement waveforms respectively. Focal mechanism from USGS. 


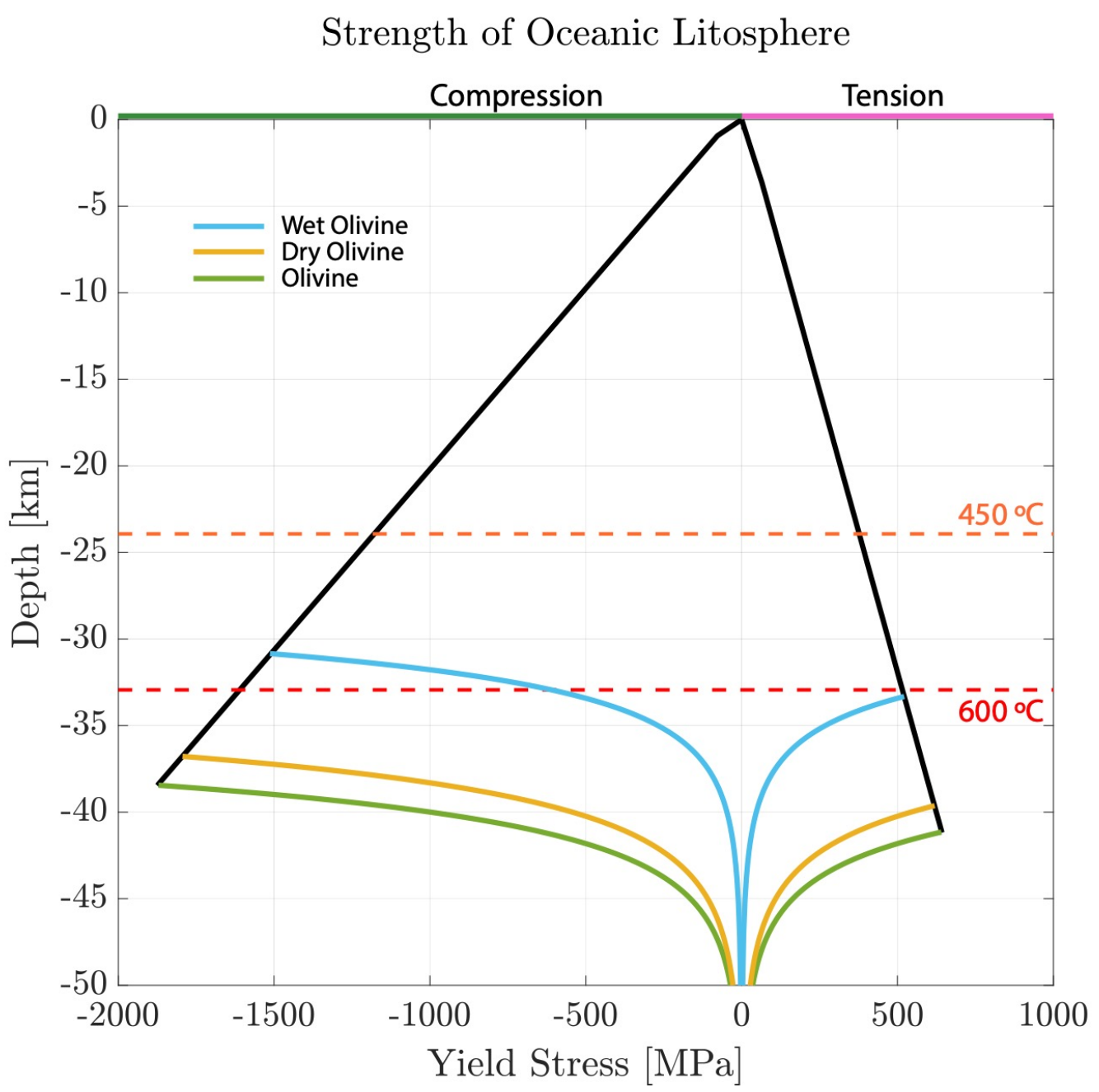

Figure 6. Yield strength envelope for an oceanic lithosphere $58 \mathrm{Myr}$ old. Stress differences or yield stress are limited at the top of

714 the plate by frictional sliding rule according to Byerlee's frictional sliding rule (black curve). Yield stress is limited at the base of

715 the plate by steady state creep, which depends on the cube of the stress and exponentially on temperature (Kohlstedt et al., 1995),

716 and computed considering steady state flow properties for olivine (green line; Goetze, 1978), dry olivine (yellow line; Karato et

717 al., 1986) and wet olivine (cyan line; Karato et al., 1986). Isotherms were computed based on the cooling of a semi-infinite half-

718 space mode (Turcotte \& Schubert, 2002). 


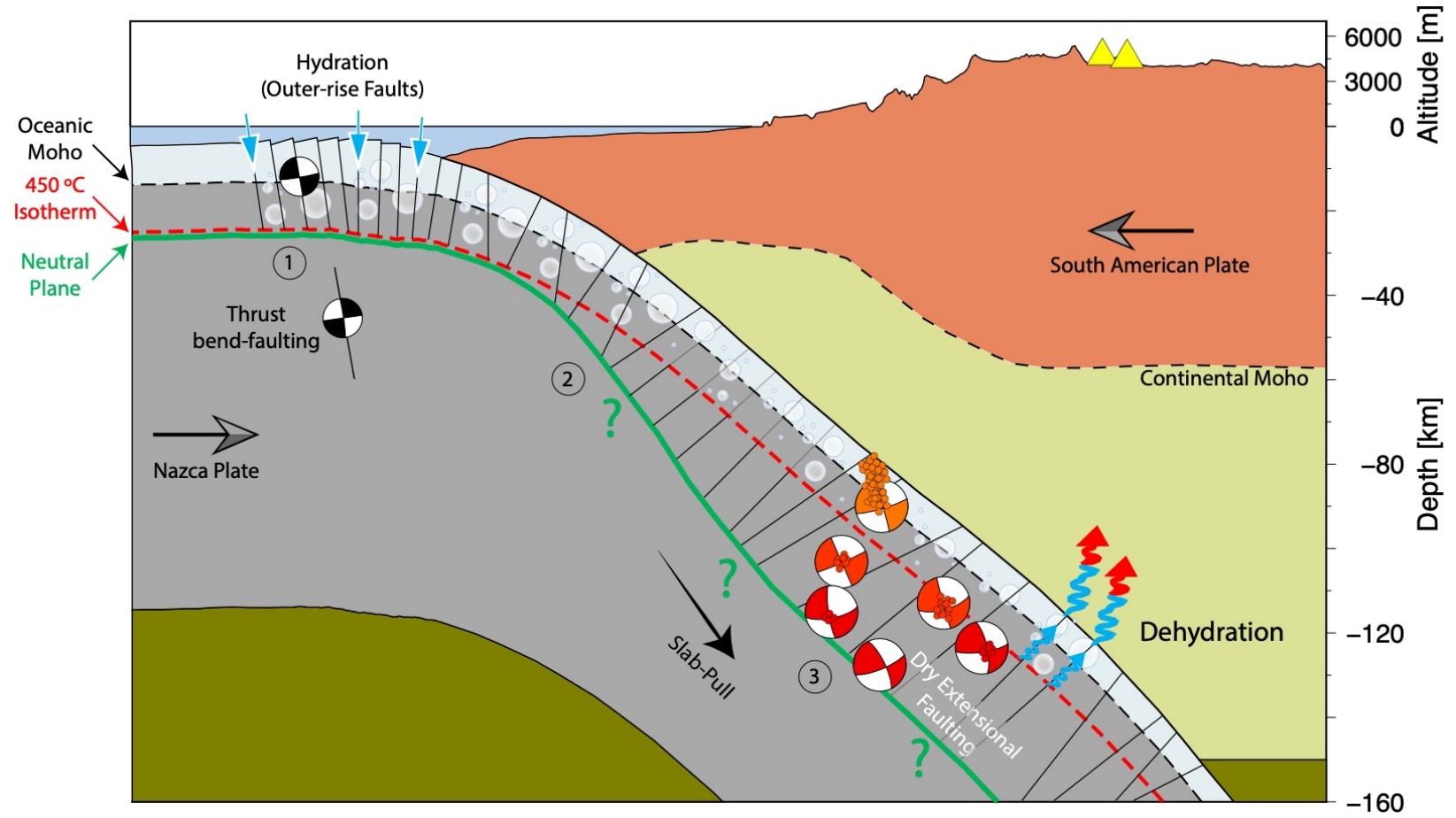

721 Figure 7. Cartoon showing a conceptual model for the the evolution of subducting lithosphere in northern Chile. The topography

722 of the plate in the outer-rise/trench region has been exaggerated to show better the deformation associated to plate bending. Scale

723 is approximate everywhere else. Bubles in oceanic lithosphere indicate hydration. 